American Journal of Applied Sciences 2 (8): 1188-1193, 2005

ISSN 1546-9239

(C) 2005 Science Publications

\title{
The Physics of Tsunami: Basic understanding of the Indian Ocean disaster
}

\author{
M.N.A. Halif and S.N. Sabki \\ School of Microelectronic Engineering, Kolej Universiti Kejuruteraan Utara Malaysia (KUKUM), \\ Jalan Kangar-Arau, 02600, Jejawi, Perlis, Malaysia
}

\begin{abstract}
This study gives a simple physics explanation behind the Indian Ocean earthquake, called December 26th's Tsunami. The explanation based on physics energy conservation and wave properties have been used to understand this phenomenon.
\end{abstract}

Key words: Tsunami, energy, wave, physics

\section{INTRODUCTION}

We might not be forgotten of a tragedy on Sunday, December 26th 2004 when the 'big-world-shocked' disaster occurred at 00:58:50 (UTC), around 6:58 a.m. (Local time), about $160 \mathrm{~km}$ from North-Sumatra, Indonesia. The Indian Ocean undersea earthquake with Richter scale magnitude $\sim 9.2$ was located off the West coast of Northern Sumatra. This is the fourth largest earthquake in the world since 1900 and is the largest since the 1964 Prince William Sound, Alaska earthquake ${ }^{[1]}$. This great earthquake caused total approximated to the hundred thousand of death in Indonesia, Sri Lanka and Thailand and we started to question what kind of freak-wave that have killed so many people. Some people know and some people don't. Then from the media, the word 'Tsunami' appeared and became more popular than the Hollywood's stars. Although the tsunami phenomena have appeared in the B.C era, the information about this disaster is not globally well-known. Japan and Hawaii are two major places where almost everybody has 'learned' about this phenomenon. Even the word 'tsunami' came from Japanese means 'Harbor Wave'. Table 1 shows the example of the historical past tsunami with the death toll ${ }^{[2]}$.

Now, let start with the definition of this freak-wave called tsunamis. Basically, Tsunami is not windgenerated waves. There are few types of tsunamis: (i) atmospheric tsunami-like waves and generated by a rapidly moving atmospheric pressure, (ii) internal tsunami-manifested as an internal wave and traveling along a thermocline, (iii) local tsunami-destructive effects are confined to coast within a hundred kilometers of the source and usually generated by an earthquake and (iv) microtsunami-small amplitude wave and not easy to detect visually. In physics point of view, a tsunami is just a shallow-water gravity wave with tiny amplitude and extremely large wavelength $\lambda$.

\begin{tabular}{llr} 
Table 1 Historical past tsunami with death toll & \\
\hline Year & Locations & Total of death \\
\hline 1605 & Nankaido, Japan & 5,000 \\
1703 & Tokaido and Kashima, Japan & 5,233 \\
1703 & Awa, Japan & 100,000 \\
1707 & Tokaido and Nankaido, Japan & 30,000 \\
1755 & Portugal and Morroco & 100,000 \\
1771 & Ryukyu Trench & \\
& (between Taiwan and Japan) & 13,486 \\
1782 & South China Sea & 40,000 \\
1868 & Chile & 25,674 \\
1883 & Krakatoa volcano explosion & 36,000 \\
1896 & Sanriku, Japan & 22,070 \\
1908 & Messina, Italy & 70,000 \\
1946 & Aleutian Island earthquake & 165 \\
& (Alaska and Hawaii USA) & \\
1960 & Great Chilean earthquake (Chile, Hawaii, & 2,000 \\
& Alaska, Philippines and Japan) & 122 \\
1964 & Good Friday earthquake (Alaska & 5,000 \\
& and Hawaii USA) & \\
1976 & Cotabato City, Philippines & 354 \\
1979 & Tumaco Tsunami (pacific coast & 2,200 \\
& of Colombia and Ecuador) & \\
1998 & Papua New Guinea Tsunami \\
2004 & Indian Ocean earthquake (Banda Aceh, & \\
& Indonesia; Tamil Nadu, Kerala, & \\
& Andhra Pradesh andaman and Nicobar Islands, & \\
& India; Sri Lanka; Thailand; Malaysia; & 300,000 \\
\hline & Somalia; Kenya; Tanzania) & \\
\hline & &
\end{tabular}

In this study, some basic conservation energy of fundamental physics has been used to understand the 'December $26^{\text {th }}$ Tsunami' phenomena. Basically, the tsunami that appeared at North-Sumatra is a local tsunami-type and caused by the undersea earthquake which the scale of magnitude may be defined as a raregreat-phenomenon earthquake ${ }^{[3]}$. One of the possibilities of this tsunami to be occurring is by the earth crack phenomena, so-called Faultline and it is slipped about $15 \mathrm{~m}$. The simple illustration is given by Fig. 1a. This phenomenon took place about $1200 \mathrm{~km}$ along the subduction zone where the India Plate dived under the Burma Plate. The India Plate is part of the great Indo-Australian Plate, which underlies the Indian Ocean and Bay of Bengal and is drifting northeast at an

Corresponding Author: M.N.A. Halif, School of Microelectronic Engineering, Kolej Universiti Kejuruteraan Utara Malaysia (KUKUM), Jalan Kangar-Arau, 02600, Jejawi, Perlis, Malaysia, Tel: +60-4-9798301, Fax: +60-49798305 
average of $0.06 \mathrm{~m} \mathrm{year}^{-1}$. The India Plate meets the Burma Plate (which is considered a portion of the great Eurasian Plate) at the Sunda Trench. At this point the India Plate subducts the Burma Plate, which carries the Nicobar Islands, the Andaman Islands and northern Sumatra. The India Plate slips deeper and deeper beneath the Burma Plate until the increasing temperature and pressure drive volatiles out of the subducting plate ${ }^{[4]}$. As we know in physics definition, the Faultline phenomenon will generate an energy $E$.

\section{PHYSICS APPROACH}

Characteristic and energy of earthquake: Basically, earthquake may occur from a volcano eruption, meteor impacts, underground explosion (nuclear test) and movement of earth plates (tectonic). But for the Indian Ocean earthquake on December $26^{\text {th }} 2004$, have been reported $^{[4]}$ that it may caused by the tectonic phenomena. It is because most earthquakes happened since this type of phenomena and it is occurred by a continuous movement of magma underneath. Here we use the possibility of tectonic phenomena by considering the Faultline type or seismic displacement. From the Faultline phenomena as presented in Fig. 1 (a), the seafloor is rapidly shifting vertically and made a huge energy to push-up the sea water from the bottom to generate maximum amplitude as indicated at the upward-wave. This behavior may be theoretically understood by the 'Waterberg' phenomena as illustrated in Fig. 1b. We may discuss this later in the next subsection. To start our understanding of physics behind the tsunamis, we may use the geophysics approach called seismology. The energy and the number of earthquakes is given by:

$\mathrm{E} \approx 10^{\mathrm{X}}$

and

$$
\mathrm{N} \approx 10^{\mathrm{Y}}
$$

where, $\mathrm{X}=4.8+1.5 \mathrm{M}_{\mathrm{L}}$ and $\mathrm{Y}=8-\mathrm{M}_{\mathrm{L}}$ Eq. (1) and (2) represents the Gutenberg-Richter (GR) conventional formula for the relationship between the released seismic strain energy $E$ and $M_{L}$, and empirical GR relation, respectively ${ }^{[5]}$. $\mathrm{E}$ is the energy and measured by unit Joule (J). Figure 2 shows the behavior of energy $\mathrm{E}$ and number of earthquakes per year versus Richter magnitude $\mathrm{M}_{\mathrm{L}}$, respectively. Inset graphs of Fig. 2a indicated the lower-edge earthquake magnitude, where the behavior is not in a horizontal line (as indicated in full figure). Even at lower Richter magnitude, the phenomena may create mega joule $\left(10^{6}\right.$ Joule $)$ of energy. Clearly shown that at $\mathrm{M}_{\mathrm{L}} \sim 9.2$ (magnitude of Sumatra tsunami), the energy is rapidly increasing. That was the reason why at $8<\mathrm{M}_{\mathrm{L}}<10$ (so-called high energy area), the earthquake caused a huge damage. From Fig. $2 b$, the curve shows the relation between the numbers of earthquake $\mathrm{N}$ at various Richter magnitudes from $\mathrm{Eq}$. (2). At lower-edge $M_{L}\left(M_{L}<2\right)$, it seems that the number of earthquakes per year happened every hour. In the other words, in theory, earth is always 'vibrating' and as mentioned before, this is caused by the continuous movement of magma underneath which is a normal behavior of earth and does not give any harm. Inset graph illustrated the $N$ versus $M_{L}$ at high-edge magnitude. The common earthquakes with magnitude $6<\mathrm{M}_{\mathrm{L}}<7$ theoretically happened 200 times per year. While for a huge impact case with $M_{L} \geq 9$ (where $C$ shows the area of Sumatra's tsunami), the probability of the huge quakes to be occurring is once every $\geq 10$ years.

Using the simple formula of (1), the energy of Sumatra earthquake $E_{E R}$ with magnitude $M_{L} \sim 9.2$ is approximated to 4exajoules (EJ) or $4 \times 10^{18} \mathrm{~J}$.

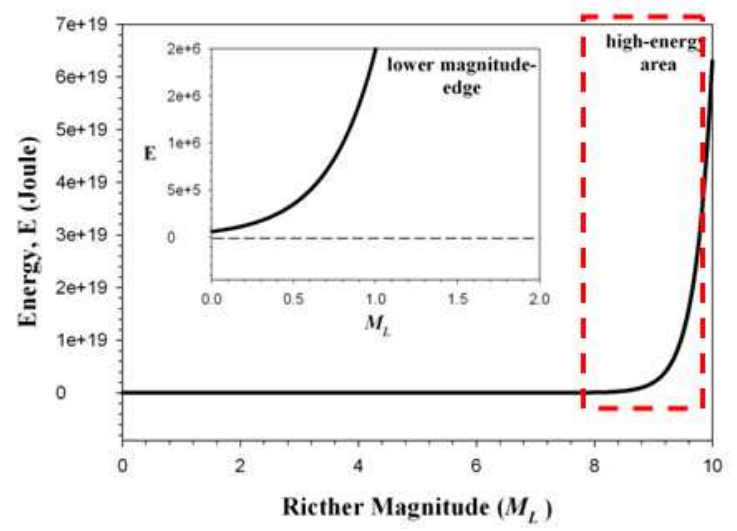

(a)

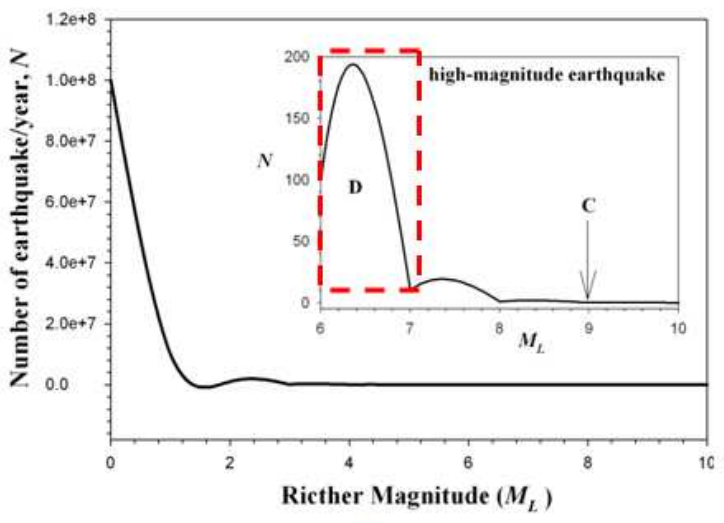

(b)

Fig. 1: Gutenberg-Richter law curves. (a) Energy $E$ and Richter magnitude $M_{\mathrm{L}}$ relation and (b) Number of earthquakes per year based on Richter magnitude. Inset graphs to (a) show the behavior at lower-edge magnitude. C and D labeled at (b) shows $26^{\text {th }}$ December's tsunami and average magnitude of earthquake happened 


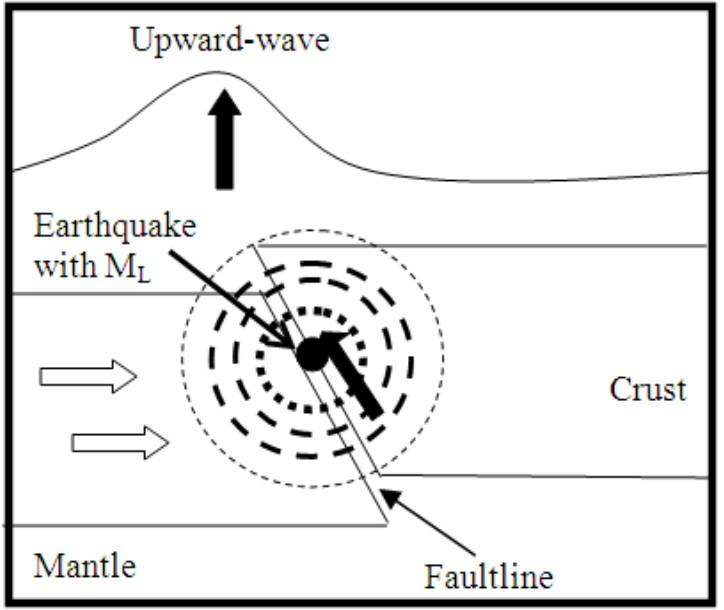

(a)

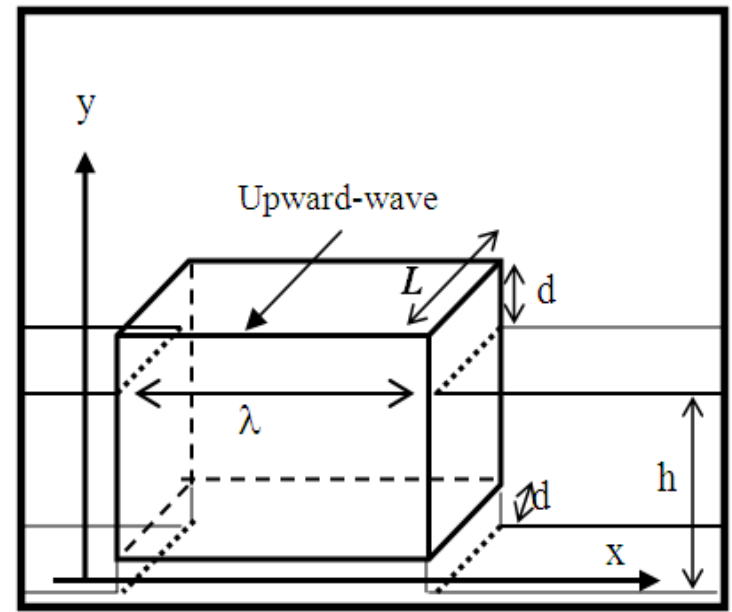

(b)

Fig. 2: Earthquake at the sea with (a) Possibility of seismic Faultline at seafloor caused by an earthquake with Ritcher amplitude $\mathrm{M}_{\mathrm{L}}$ and (b) Water volume from fautline effected called box-shaped 'Waterberg' ${ }^{[10]}$ (a). $\mathrm{d}$ is the height of the vertical shift, $\mathrm{h}$ is a depth of the sea, $\lambda$ is the wavelength within the box and $L$ is the length of the box

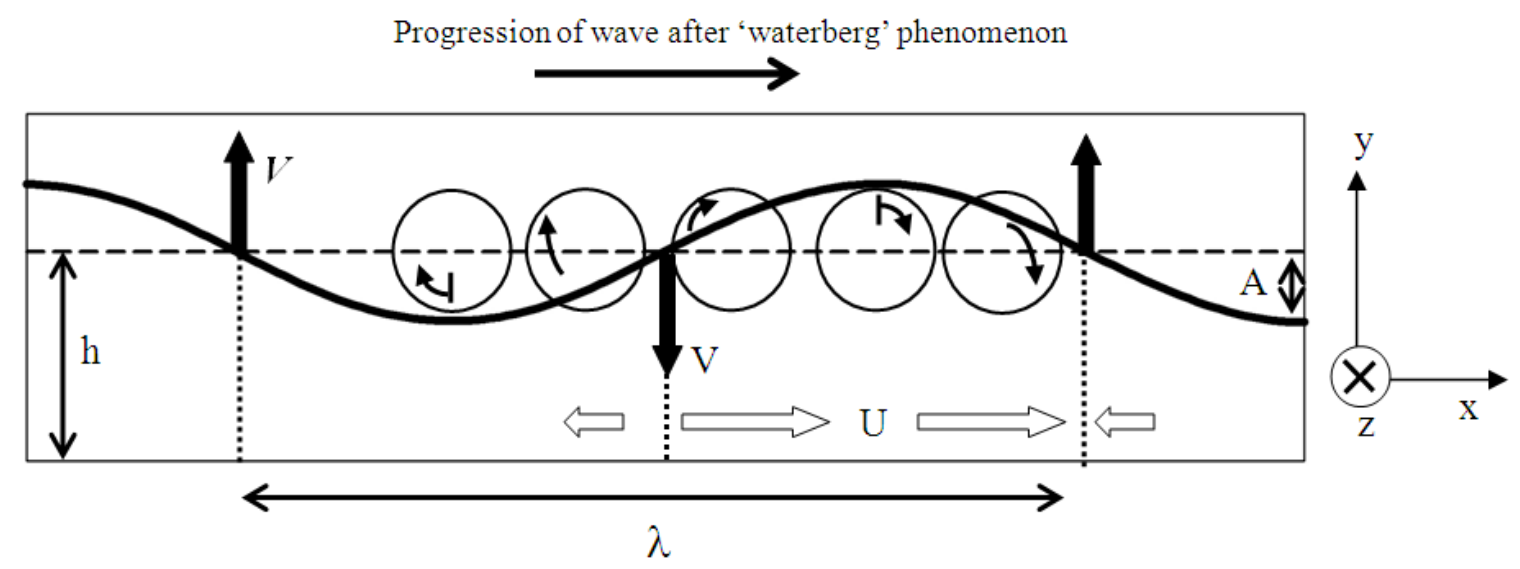

Fig. 3: Illustration of movement of tsunami wave with wavelength $\lambda$ and amplitude A that propagated to the right hand-side initially after the 'waterberg' phenomena. The movement of the wave is represented by the black arrow and white arrow as the horizontal velocity $\mathrm{V}_{\mathrm{H}}$ and vertical velocity $\mathrm{V}_{\mathrm{V}}$, respectively. The depth of the sea is $\mathrm{h}$. The round movement shows the ripple movement where it collected more molecules

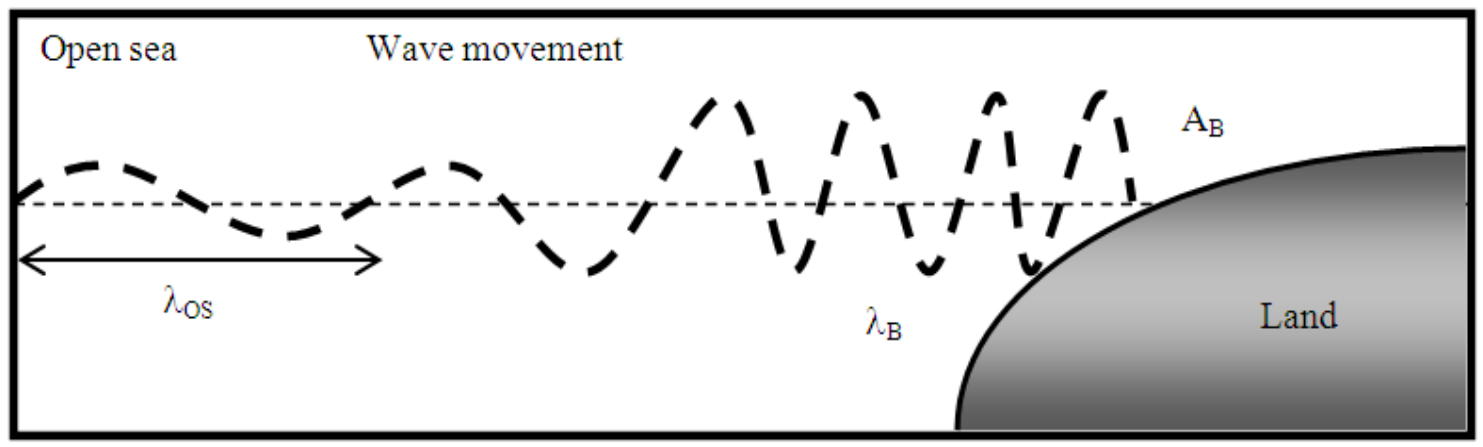

Fig. 4: Simple illustration of tsunami wave behavior when it reaches the land. $\lambda_{\mathrm{OS}}$ and $\lambda_{\mathrm{B}}$ represented the open sea and nearbeach wavelength, respectively, while $A_{O S}$ and $A_{B}$ defined the amplitude of the tsunami wavelength at open sea and nearbeach, respectively 
Am. J. Applied Sci., 2 (8): 1188-1193, 2005

Table 2: Ocean depth information with average speed of tsunami wave

\begin{tabular}{llll}
\hline Ocean & Average depth $(\mathrm{m})$ & Deepest depth $(\mathrm{m})$ & Speed of tsunami waves, $v\left(\mathrm{~km} \mathrm{~h}^{-1}\right)$ \\
\hline Pacific Ocean & 4,637 & Mariana Trench $=11,033$ & $766.8<v<1184.4$ \\
Atlantic Ocean & 3,926 & Puerto Rico Trench = 8,605 & $705.6<v<1044.0$ \\
Indian Ocean & 3,963 & Java Trench $=7,725$ & $709.2<v<990.0$ \\
Southern Ocean & 4,000 to 5,000 & The southern end of the Southern Sandwich Trench $=7,235$ & $712.8<v<957.6$ \\
Arctic Ocean & 1,205 & Eurasia Basin $=5,450$ & $388.8<v<831.6$ \\
\hline
\end{tabular}

By comparing it to the energy of trinitrotoluene (TNT) explosion, where 1 tons of TNT $\sim 4.184 \times 10^{9}$ Joules or 4.184 GJ, thus the energy of Sumatra earthquake is approximated to $1 \mathrm{GT}$ of $\mathrm{TNT}^{[6]}$. This huge-energy earthquake may increased by the energy of the massive displacement of crustal material shown in Fig. 1a. To be clear, back to the history of World War II, the Sumatra earthquake is approximated to 80,000 of Hiroshima "Little Boy" types of atomic bombs by comparison to the explosion energy. (Hiroshima's atomic bomb energy released equally 12.5 kilotons of $\left.\mathrm{TNT}^{[7]}\right)$. Now, let us consider the energy from the 'Waterberg' phenomena from Fig. 2b. Because of the Faultline-seafloor-effect where it shifted vertically, we may assume that at the short duration of the earthquake, the overall mechanical energy in the water is to be the same. However, it may correspond to the distribution of potential $U$ and kinetic energy $K$, respectively. From the effect of the energy of earthquake at the seafloor, the volume of the water above the active area is vertically-shifted with the seafloor. The volume of the water is theoretically assumed to be in box-shape and at the upwards-wave; the 'Waterberg' is at the maximum level. In physics approach it has a maximum $U$ with the minimum K. From Lautrup ${ }^{[8]}$, the original water column is in buoyant equilibrium with the surrounding sea. Thus we only need to estimate the $U$ of the appearance box-shaped 'Waterberg' at the sea surface with height $d$ ' and wavelength or width of $\lambda$ and boxshaped length of $\mathrm{L}$ after displacement phenomena. The particles average of 'Waterberg' is lifted over the sea surface at $d^{\prime}=d / 2$. From the basic physics of mechanics and density definition ${ }^{[9]}$, the potential energy of the box-shaped 'Waterberg' $\mathrm{U}_{\mathrm{W}}$ may be written as:

$$
\mathrm{U}_{\mathrm{w}}=\frac{1}{2} \rho_{\mathrm{w}} \mathrm{gL} \lambda \mathrm{d}^{2}
$$

where, $\rho_{\mathrm{W}} \approx 1000 \mathrm{~kg} \mathrm{~m}^{-3}$ is the water density. Because of the conservation of energy in physics laws, the boxshaped at seafloor with a similar dimension has a similar potential energy $\mathrm{U}_{\mathrm{WF}}$. From 2004 Indian Ocean earthquake data ${ }^{[4]}, \mathrm{L} \sim 1200 \mathrm{~km}$ and $\lambda \sim 150 \mathrm{~km}$ and from simulation data of the Russian Tsunami Laboratory in Novosibirsk, we may use $\mathrm{d} \sim 5 \mathrm{~m}$. Using standard gravity acceleration $\mathrm{g}=9.8 \mathrm{~ms}^{-2}$, from Eq. (2), the total energy that has been deposited in the water is $\mathrm{E}_{\mathrm{w}} \approx \mathrm{U}_{\mathrm{W}} \approx 2 \times 10^{16} \mathrm{~J}$ or 20 petajoules. Again, in physics, the volume of water for box-shaped 'Waterberg' is pushed-up at the maximum $U$ by the radiant energy of an earthquake. From the conservation of energy, where energy can not be destroyed but it may be transferred, the ratio percentage of the water energy and earthquake radiation energy is $\mathrm{E}_{\mathrm{W}} / \mathrm{E} \sim 1 \%$. Thus another 99\% may be transferred in other types of energy, i.e. Kinetic energy, heat and may absorb by the crustal and mantle at the seafloor. Just imagine that the 20petajoules of scraping-up box-shaped 'Waterberg' energy is only $1 \%$ of the whole earthquake radiation energy and this upward-wave is ready to stand-by towards an aggressive-traveling to primarily 'harbors' i.e., North Sumatra and Sri Lanka.

Tsunami waves: So what was the speed of the Tsunami that hit parts of South-East Asia on December 26,2004 ? It actually depends on the location of the quake on the ocean which caused the channel flow of water begun, causing a shallow-water wave. From the theory of waves, we know that wave move energy, not matter. Let us consider the movement of tsunami wave initially after the phenomena of 'Waterberg' mentioned earlier. Figure 3 shows the progression of a wave to right-hand side. The round movements show the water surface's stretch and generate the ripples (capillary wave) that collected more molecules when it moves. There are two directions of velocity: horizontal velocity in the $\mathrm{x}$-direction and vertical velocity in the $\mathrm{y}$-direction represented by $V_{H}$ and $V_{V}$, respectively. As we know, the established amplitude of tsunami wave $\mathrm{A}$ is in this condition, where $\mathrm{A} \leq \mathrm{h} \leq \lambda$. Before we go any further about the speed of a tsunami wave, let us consider the energy of tsunami wave corresponded to the Fig. 3. As usual, using the same approach of 'Waterberg' energy, the tsunami energy $E_{T w}$ may be calculated using the amplitude of wave $\mathrm{d}=\mathrm{A} \approx 1.5 \mathrm{~m}^{[8]}$, thus $\mathrm{E}_{\mathrm{TW}} \approx 2 \times 10^{15}$ with $\mathrm{L} \approx 1200 \mathrm{~km}$ and $\lambda \approx 150 \mathrm{~km}$. The amount of energy here represented about $10 \%$ of the 'Waterberg' energy caused by undersea earthquakes. It is shown that from radiation earthquake energy, the amount of energy is decreased where the characteristics may be written as $\mathrm{E}_{\mathrm{TW}}<\mathrm{E}_{\mathrm{W}}<\mathrm{E}_{\mathrm{ER}}$. By considering the single wave movement with $\lambda$ and assumed that the tsunami wave also in the box-shaped-type where the volume of water moving up must be comparable with coming down according to the $\mathrm{V}_{\mathrm{V}}$ and $\mathrm{V}_{\mathrm{H}}$, respectively. Using the physics approach at single wave in Fig. 3 with the potential and kinetic energy and also by considering wave properties to a local elliptical motion of water particles $^{[8,10]}$, the speed of swallow water wave is defined as: 
$\mathrm{v}=\sqrt{\mathrm{gh}_{\mathrm{w}}}$

This equation clearly shown that the speed of a tsunami wave is corresponding to the depth of the sea $\mathrm{h}_{\mathrm{w}}$. For example, in the Indian Ocean ${ }^{[11]}$, where the typical water depth is about $3963 \mathrm{~m}$, a tsunami travels approximated to $197 \mathrm{~m} \mathrm{~s}^{-1}$ or $709 \mathrm{~km} \mathrm{~h}^{-1}$ and the wave period of $\mathrm{t}=\lambda / \mathrm{v} \approx 761 \mathrm{~s}$ approximated to 13 minutes. The speed of tsunami in the Indian Ocean is comparable to the speed of a Boeing 737. As recorded, the South EastAsia tsunami moved up at speeds up to $800 \mathrm{~km} \mathrm{~h}^{-1}-$ which means that it must have come from depths of about $5,000 \mathrm{~m}$. This phenomenon of speed shows that it may move from one side of the Indian Ocean to the other side in less than one day. Table 2 indicated the information about the depth of the main world ocean ${ }^{[11]}$ with the average speed of a tsunami wave. In the deepest depth of the Indian Ocean, called Java Trench, speed of a tsunami wave is almost $1000 \mathrm{~km} \mathrm{~h}^{-1}$ with the wave period $t \approx 9$ minutes. While for the world deepest ocean depth, i.e Mariana Trench of Pacific Ocean, $v \approx 1184 \mathrm{~km} \mathrm{~h}^{-1}$. It is larger than the speed of a Boeing 747 . We might say that, it will be a huge impact for North and South America as well as Japan, the Philippines and Australia if tsunamis appear in this area. Overall data shows that, average speed of a tsunami wave is from speed of F1 car (Arctic Ocean) to larger than the speed of a fighter jet.

\section{LAND APPROACH}

From our earlier calculations of radiation earthquake energy using RG formula, 'Waterberg' energy and tsunami wave energy, we have represented that the energy is decreased. This phenomena called energy loss, where wave loss their energy away from its source. An energy loss rate may be defined using the amplitude of tsunami wave with a relation called Green's law ${ }^{[8]}$ as $A \sim \lambda^{-1 / 2}$, where when the shallow tsunami moving near the land, $\mathrm{A}$ is increased when the $\lambda$ is decreased. Figure 4 illustrated this phenomena with wavelength near the beach $\lambda_{B}$ is less than the wavelength at open sea $\lambda_{\mathrm{OS}}$. The definition of energy loss in (6) indicated this situation; large $\lambda$ gives less energy loss. When a tsunami wave approaches the coastal region (where depth $h$ and $\lambda$ decreased), the speed of wave $v$ may also decreased. Let us consider a location in the Sumatra coast to a water depth of $10 \mathrm{~m}$, the speed would be $\sim 10 \mathrm{~m} \mathrm{~s}^{-1}$ (about $36 \mathrm{~km} \mathrm{~h}^{-1}$ ), which is a drastic reduction than the speed in the open ocean but the wave would still be difficult to be outran even for a swimmer or a running person. From Fig. 4, the amplitude of tsunami wave $A_{B}$ is much greater, one of the reasons that give a high damage to the land. On the other hand, from Fig. 3, when ripples move, it may collect more molecules, thus, when the tsunami wave travels towards land, it will increase the mass of waves.
Then, we might see this phenomena as a momentum $p$ rate, so-called impulse I. Using the simple physics law, since there is a changing of speed within the traveling time $\mathrm{T}$, thus from impulse definition, $\mathrm{I}=\Delta \mathrm{p}|\mathrm{T} \approx| \mathrm{mv}-$ $\mathrm{mu} \mid / \mathrm{T}$. Traveling time of tsunami wave towards North Sumatra (less than 1 hour) and Sri Lanka (2 hours) is less than the African Coast ( 7 hours). It gives us a clear view to the huge impact of tsunami waves of North Sumatra and Sri Lanka compared to the African Coast.

Tsunamis propagate outward from their source, so coasts in the "shadow" of affected land masses is usually fairly safe. They also need not be symmetrical; tsunami waves may be much stronger in one direction than another, depending on the nature of the source and the surrounding geography. Local geographic peculiarities can lead to seiche or standing waves forming, which can amplify the onshore damage. For example, the tsunami that hit Hawaii on April $1^{\text {st }} 1946$ had a 15 minute interval between wave fronts. The natural resonant period of Hilo Bay is about 30 minutes. Meant that in every second wave was in phase with the motion of Hilo Bay, creating a seiche in the bay. As a result, Hilo suffered worse damage than any other place in Hawaii, with the tsunami/seiche reaching a height of $14 \mathrm{~m}$ and killing 159 inhabitants ${ }^{[12]}$.

\section{CONCLUSION}

We already presented the simple physics approach to understand the tsunami phenomena initially after the undersea earthquake until it reaches the land. As we calculated, the energy $\mathrm{E}$, velocity $\mathrm{v}$ and wavelength $\lambda$ of tsunamis are decreased but the amplitude of tsunami wave $\mathrm{A}$ is increased when it reaches the land, respectively. The changing of wave height when its close to the shore makes tsunamis difficult to be detected at an early stage. From our first calculation of the radiation earthquake energy using GR formula, the huge 'explosion' energy undersea at 00:58:50 (UTC) or $160 \mathrm{~km}$ from North Sumatra is approximated to 1 gigatons of TNT equivalent to 80,000 "Little-Boy" Hiroshima atomic bombs and then this big amount of energy transfer only $1 \%$ to the 'Waterberg' energy (about 800 types of Hiroshima atomic bomb), where it is an initial area of tsunami wave to propagate. Then when it moves, the tsunami wave energy is only $10 \%$ (megajoules) from 'Waterberg' or approximated to 80 Hiroshima atomic bombs and the speed around Boeing's velocity at the open sea with a large wavelength. This 'energy packages' will decrease based on energy loss phenomena as we have mentioned earlier and the velocity is much slower compared to the open sea when it reach the land.

In this study, we also proposed that the impact of tsunamis with less velocity compared to the open sea behavior is because of the changing of momentum rate implus, $\mathrm{I}=|\mathrm{mv}-\mathrm{mu}| / \mathrm{T}$. Mass of waves are increased 
based on the ripple movement that collect more molecules during the traveling period. The damages and death tolls from three different areas shown that, traveling time of tsunami towards North Sumatra is less than Sri Lanka and African coast. From different points of view, when the tsunami reaches land, the amplitude of waves grows and resulting flood at the beach and coastal area and if it is more than one wave, it may cause a big-flood water phenomena at the land.

The world-shock disaster that happened on December $26^{\text {th }} 2004$ so-called Indian Ocean Tsunami caused an estimated 300,000 or more deaths and extensive damage due to run-up, landward inundation and wave-structure interactions. Even though the scientist has built a good 3-D numerical model to detect tsunami phenomena, but the tectonic motion phenomena undersea cannot be derived reasonably from available seismic data. Recently after the tsunami, there were a lot of rumors about this disaster. Some people say about the non-scientific reason and lots of them correspond this issue towards the religion terms. Even the explanation behind these phenomena may be studied using the physics approach, but it seemed to be realistic before the tsunami hits the land. We however agreed to the situation that sometimes we may explain something, but sometimes we may not. This hugeimpact disaster may inquire us to be back to our religion. From Einstein's quote: "Science without religion is lame, religion without science is blind". We should relate our investigation here together with our religion. Of course to understand God's mind is an infinite solution, it's just like a computer wants to understand its creator, the human kind. It is limited to its memory capacity. It is the same for us to understand tsunamis phenomena deeply that we may solve it, but not as perfect as it is. For us, there are lots of physics studies might be done to understand the tsunami phenomena, because it is 'always have a plenty of room at the bottom'.

Although, the earthquake phenomena are usually a common phenomena to Indonesian, but now after the Sumatra tsunami on December $26^{\text {th }}$, it may be a worldwide issue especially to other South East Asian countries like Malaysia, Singapore and Thailand. The fact that Malaysia and Singapore are the safest countries from earthquake phenomena is no longer true. The 'lesson' that we have learned at the end of the last year disaster is really giving us a new lesson to have a 'better' preparation in the future action. Although, the Indian Ocean tsunami emerged about 6 months ago, the 'unforgettable moments of December 26 ${ }^{\text {th }} 2004^{\prime}$ should always remains in our heart forever and ever.

\section{ACKNOWLEDGMENTS}

The author would like to thank Assoc. Professor Dr Benny Lautrup from The Neils Bohr Institute, University of Copenhagen, Denmark for explanation of
'Waterberg' phenomenon. Thank also to Dr Maged Mahmoud Marghany from Kolej Universiti Sains and Teknologi Malaysia (KUSTEM) for some comments on this article and Assoc. Prof. Dr Zul Azhar Zahid Jamal, Dean of Microelectronic Engineering, KUKUM, for his support and corporation. We tribute this study to those who are affected by the Indian Ocean Tsunami last year.

\section{REFERENCES}

1. Asian Tsunami/Tiger Waves, 2005. http://www.globalsecurity.org/eye/andaman.htm $(25 / 5 / 2005)$.

2. Tsunami, 2005. http://en.wikipedia.org/wiki/Tsunami (25/5/2005).

3. Ritcher magnitude scale, 2005. http://en.wikipedia.org/wiki/Richter_scale (26/5/2005).

4. 2004 Indian Ocean Earthquake, 2005.http://en.wikipedia.org/wiki/2004_Indian_Oc ean_earthquake (26/5/2005).

5. Gutenberg, B. and C.F. Ritcher, 1954. Seismicity of the Earth and Associated Phenomenon. $2^{\text {nd }}$ Edn. Princeton University Press, Princeton.

6. Megaton, 2005. http://www.answers.com/topic/megatonl. (27/5/2005).

7. Damages Caused by Atomic Bombs, 2005. http://mothra.rerf.or.jp/ENG/Abomb/History/Damages. html (27/5/2005).

8. Benny Lautrup, Tsunami Physics, 2005. http://www.nbi.dk/ lautrup/continuum/tidbits/tsun ami.english. (27/5/2005).

9. Halliday, D., R. Resnick and J. Walker, 1997. Fundamentals of Physics (Extended). John-Wiley and Sons, New York.

10. Margaritondo, G., 2005. Explaining the physics of tsunamis to undergraduate and non-physics students. Eur. J. Phys., 26: 401.

11. Earth's Ocean: An introduction, 2005. http://www.enchantedlearning.com/subjects/ocean/ $(30 / 5 / 2005)$.

12. The 1960 Tsunami, Hilo, 2005. http://hvo.wr.usgs.gov/volcanowatch/1994/94_05_ 20.html (30/5/2005). 